\title{
An Investigation of the Integrated Quality Management System (IQMS) in South African Primary Schools: The Teachers' Voices
}

\author{
Bobo Segoe \\ Department of Curriculum and Instructional Studies \\ South Africa \\ segoeba@unisa.ac.za
}

\section{Doi:10.5901/mjss.2014.v5n9p724}

\begin{abstract}
The purpose of this study was to investigate the implementation of the IQMS in South African schools from the teachers' perspective. This was done by interrogating the context and the content of policy documents as well as focussing on the training and the functioning of the structures involved in the implementation of the IQMS. Thereafter, the perceptions, feelings and experiences of teachers regarding IQMS were captured. A literature study, observation as well as documents analyses and interviews were used to gather information through a qualitative method. Six primary schools were purposefully selected from one South African province, namely North West. Focus group interviews of four teachers per school, followed by individual semi-structured interviews of two teachers per school, were held. These were integrated with the analyses of policy documents and records at those schools. Although it appears from findings that the appropriate structures for implementation are in place in some schools, the policy document and prescribed steps were not followed. Furthermore, teachers cited some anomalies and difficulties with regard to the implementation of IQMS. It was discovered that some teachers have a negative attitude towards the IQMS. The majority of the schools do not have management plans for the implementation of the IQMS. Consistency and follow-ups are sadly lacking. Most teachers cited that the success of the implementation depends largely on whether the District Office, the school principal, the Staff Development Team and the Development Support Group play their roles effectively.
\end{abstract}

Keywords: Integrated Quality Management system, education system, teachers, implementation, district office

\section{Introduction}

IQMS is a teacher evaluation system which was implemented in South African schools in 2005. This was a clear reaction to the autocratic mode of evaluation that operated during the apartheid era and it is a major shift from the old paradigm of external evaluators. Biputh (2008) asserts that this paradigm calls for a joint collaboration between schools and local districts with the overall aim of improving teacher evaluation and the standard of South African education and to address the inequalities and injustices of the past.

A great deal of literature on staff evaluation covering a wide spectrum of fields such as industry and commerce, including schools, has been done and it generally identifies three main categories of quality evaluation. Firstly, evaluation is conducted to review performance, identifying strengths and weaknesses. Secondly, it provides information about the service in order to improve the quality of the service and to demonstrate accountability. Thirdly, evaluation is aimed at encouraging personal and professional development.

Based on the above, it follows that the pedagogic and social reasons for assessing teachers must go beyond simply finding out whether teachers possess technical skills. For instance, evaluation should improve the life chances of the most disadvantaged learners by showing where more human and financial resources are necessary. Thus evaluation must be concerned with social justice both inside and outside the classroom. Since its introduction, very little research been carried out to establish whether IQMS model of evaluation addresses that which it was intended to. This study evaluates the extent to which teachers perceive the implementation of IQMS as a strategy for teacher evaluation in South Africa.

The first section of the study gives a brief description of the background and the context of this work, highlighting the overview and the importance and aspects of teacher evaluation as an important component of teaching and learning based on the literature reviewed. This is followed by the research methodology and the findings from fieldwork conducted with 24 primary school teachers in South Africa. The findings are discussed with the focus on distinct areas of the implementation of the IQMS in South African Primary Schools. At the end of this work, concluding remarks are presented. 


\section{Background to the Study}

The education system during the apartheid era was complex as there were fifteen education departments, reflecting the racially fragmented society, with a differentiated system of inspection, control and appraisal across these departmental sectors (Educators Workload Report, 2005). The relationship between teachers and the inspectorate varied considerably across these education departments. Fullan (1992:2) asserts that "Educational reform is complex, non-linear, frequently arbitrary, and always highly political. It is rife with unpredictable shifts and fragmented initiatives". This was perhaps nowhere as true as it was in South Africa. As with most aspects of South African education, the issue of quality assurance or appraisal has been complicated by the legacy of apartheid (Biputh, 2008).

On the whole, the apartheid appraisal system during apartheid was geared towards control and containment of learners and teachers, rather than their development and support (Weber, 2005). There is consensus in the literature regarding the importance of effective development programmes for teachers (Loxley et al 2007, Sandberg, Ansett \& Wahlgren, 2007). Even at school level, the leadership of principals in professional development activities should be given a particular attention in order to create a school climate wherein schools' curricula and administrative issues receive collaborative attention by all the teachers in the school.

In a study by Menlo and Poppleton (1990) it was clearly argued that the single most significant factor why teachers should be professionally developed is based on the conviction that the quality of teachers influences the quality of the learners' experience and achievement in a positive way. Mestry et al (2009) believe that raising the quality of teacher performance through teacher development programmes, such as IQMS, is essential to improve the overall performance of the education system, which makes the debate about school-type, school-by-school performance, class size, among others, look irrelevant. However, in South Africa the culture of professional development, by then, had been severely affected by the legacy of apartheid education.

The apartheid department of education and training encountered political resistance to teacher evaluation and appraisal because many inspectors and principals were viewed as being politically biased collaborators with the apartheid regime (Mestry, 1999). According to Phillips (1996), the secrecy which surrounded the whole system created enormous malcontent and the possibility of evaluation and appraisal acting as an incentive was severely negated. During this apartheid time, teachers were the sole decision-makers in the classroom and would dictate the entire implementation of teaching and learning with very little development (Dhlamini, 2009). The education was "highly bureaucratized with strict control through standardised procedures, codes and lines of responsibility" (McLennan 2000 cited in Smith \& NgomaMaema, 2003: 352). Black schools suffered under a regime of inspection and teacher evaluation which were autocratic. Judgemental, summative forms of evaluation, inspection and appraisal seemed to have proliferated in black schools. It became evident that a new model of appraisal was required. The new appraisal system was negotiated between the Department of Education and teacher unions as from 1992 and was piloted in 1995 and 1996 and the findings were released in 1997 (Biputh, 2008).

The pilot revealed that the new teacher appraisal system could be applied in all schools in South Africa irrespective of the vast differences of contextual conditions. The essential elements of the new proposed system of evaluation and appraisal included self-evaluation, peer review, consideration of contextual factors and mediation, only in the event of a conflict, by an inspector. The system was linked to a developmental plan for the individual teacher, and linked in turn to more general school development planning (Swartz, 1994). It was also felt that the new appraisal system would contribute significantly to facilitating relations between teachers and school management and between schools and departmental offices (DoE, 1999). The final agreement for a new educator appraisal system, namely the Integrated Quality Management System (IQMS) was reached in 2003 (Educators Workload Report, 2005).

IQMS, as a professional development model in South Africa, is seen as a process by which teachers review, renew and extend their commitment as change agents to the moral purposes of teaching; and by which they acquire and develop their knowledge, skills and attitudes (Day, 1999). Craft (2000) adds that there are many reasons for undertaking professional development, such as to improve the job performance skills of an individual, extend the experience of an individual teacher for career development or promotion purposes as well as to develop the professional knowledge and understanding of an individual teacher in order to fulfil his or her responsibilities more effectively. Mestry et al (2009) suggest that teacher development activities provide the means for teachers to experience continuing education as part of a team of professionals. Therefore, teacher development programmes should be about school improvement and professional growth (Joyce, 1993). Guskey (2000) and Elmore (2001) emphasise that teacher development programmes are the process by which teachers learn to be more effective and efficient. These authors further agree that the essential purpose of teacher development programmes is to improve the whole school system and not just the individuals thereof.

The IQMS combines the three programmes that have been discussed over several years by the major 
stakeholders and it is aimed at the teachers and the schools as follows:

- Developmental Appraisal (DA) which its purpose is to appraise individual educators in a transparent manner with a view to determining areas of strength and weakness, and to draw up programmes for individual development

- Performance Measurement (PM) which should evaluate individual teachers for salary progression, grade progression, affirmation of appointments and rewards incentives

- Whole School Evaluation (WSE) which evaluates the overall effectiveness of a school, including the support provided by the district, school management, infrastructure and learning resources as well as the quality of teaching and learning (NDOE, 2000).

Weber (2005) states that the philosophy underpinning the IQMS is based upon the "fundamental belief' that the purposes of its measures are to:

- Promote accountability

- Monitor the school's overall effectiveness

- Provide support and opportunities for teacher development to assure continued growth

- Assess strengths and areas for development and

- Determine competence

The IQMS pays careful attention to integrating the three constituent programmes; Developmental Appraisal and performance Measurement are supposed to complement one another, "without duplication of structures" (ELRC, 2003:4). On the other hand, Performance Measurement and Developmental Appraisal have to be completed in one school year. Both are linked to Whole School Evaluation. Thus IQMS aims at identifying specific needs of teachers, schools and districts; providing support for continued growth, promoting accountability, monitoring the school's overall effectiveness and evaluating teachers' performance. IQMS further assumes that most teachers recognise the need for, and responsibility to improve themselves professionally (DoE, 2009). Hence the implementation of IQMS implies that professional development should be placed high on the school's agenda, and that IQMS and professional development are highly intertwined.

\section{Research Method}

\subsection{Research questions}

The research questions for this study were as follows:

- What are the perceptions of South African primary school teachers about IQMS?

- How is IQMS implemented in South African primary schools?

Following Maxwell's (1996:17) understanding of qualitative research and its purposes, the researcher utilised this approach in order to:

- Understand the meaning, for participants in the study, of events, situations and actions they are involved in and of the accounts that they give of their lives and experiences

- Understand the particular context within which the participants act, and influence that this context has on their actions

- Understand the process by which events and actions take place

- Identify the importance of the phenomenon and its influences

As such, the researcher focussed his study examination in similar institutional settings, referred to as primary schools situated in the North West Province, being one of the nine South African provinces which were set up post apartheid era. Qualitative research takes place in a natural setting and the researcher has face-to-face interaction with participants. McMillan \& Schumacher (2010:23) support this naturalistic nature of the qualitative approach when they contend that "the qualitative research approach emphasises gathering data on naturally occurring phenomena. Most of these data are in the form of words rather than numbers, and in general, the researcher must search and explore with a variety of methods until a deep understanding is achieved". In addition, qualitative research design is an inquiry process of understanding based on distinct methodological traditions of inquiry that explore a social or human phenomenon (Matee, 2009). 


\subsection{Participants}

The participants of this study were twenty four primary school teachers from six primary schools in the North West Province (South Africa). The researcher used the process of purposeful convenience sampling; the teachers taught in different Grades with different age groups, different experiences and are teaching in rural and urban primary schools of the North West Province. These teachers were considered "information rich". Minott \& Willet (2011) state that information rich participants are able to illuminate or provide a great deal of insight into the issues of central importance to any study. Participants were told about the nature of the research and how the data would be utilised, were promised anonymity and confidentiality, that the data would be kept in a safe place and that it would not be made available to any other person.

\subsection{Data collection process}

Firstly, focus groups of four teachers per school were chosen, because compared to other forms of qualitative methods, they permit analysis not only of statements and reports of experiences and events, but also of the instructional context in which these statements and reports are produced (Flick:2007). Additionally, it has been argued that "focus groups may provide quality controls because participants tend to provide checks and balances on one another that serve to curb false or extreme views" (Patton, 2002:67). Secondly, from each group at a particular school, two teachers were purposefully selected and each was requested to participate in an individual interview so as "to probe and go deeper into the motivations of respondents and their reasons for responding as they do" (Cohen et al, 2002: 268). IQMS documents were also analysed so as to gather more information regarding the implementation of IQMS at the identified schools.

\subsection{Data analysis}

Interview session discussions were audio-taped and then transcribed verbatim. Thereafter, the constant comparative method (Merriam, 1998) was used to analyse the focus group data. The constant comparative analysis allows a researcher to format and transcribe the data into a readily identifiable, readable and structured format. This analysis uses systematic steps of identifying key points, followed by comparing these points with those of other interview group members in order to identify patterns (Meegan et al, 2013). This structure ensured that whatever was presented was an accurate reflection of the participants' interviews.

Data was reduced in order to determine themes so as to understand the larger dynamics about the implementation of IQMS in South African Primary Schools in the North West Province. Using the constant comparative method, similar themes from the six schools were grouped together under headings. In this way, areas of importance and significance in relation to the implementation of IQMS and the teacher perceptions were identified.

Merriam (1998) asserts that providing readers with a rich, thick description permits them to determine how closely their situations match the research situation, and hence, whether findings can be transferred. The use of in-depth description in portraying a particular phenomenon allows for transferability by the reader, thus enhancing external validity. External validity was achieved in the present study by providing rich, thick descriptions through direct quotes from teachers regarding their experiences and perceptions of the implementation of IQMS in their schools.

\section{Results and Discussion}

Results are categorised into four themes that emerged from the data: (a) Availability of IQMS policy documents, (b) selfevaluation/appraisal (c) peer evaluation/appraisal and (d) feedback from stakeholders.

\subsection{Availability of IQMS policy documents}

In all schools, policy documents such as Integrated Quality Management System (Training Manual) and the Manual for Performance Indicators (Friendly Rating Guide) were available. The contents of these booklets explain clearly how IQMS has to be implemented at school level. For example:

- The district office is to receive consolidated reports of individual teachers from the school, process them and give feedback to the school

- The principal has to ensure that the IQMS is implemented uniformly and effectively and also make sure that all teachers have read and understood all IQMS policy documents

- Together with the Staff Development Team (SDT) and Senior Management Team (SMT), the principal must 
facilitate advocacy, training at school level and should conduct internal moderation of evaluation results

- The SMT must monitor the whole process and assist with the broad planning and implementation of the IQMS and also ensure that teacher evaluation is done in line with the policy documents

- The teachers must avail themselves, undertake self-evaluation and engage in the process of feedback and discussion after teacher evaluation

- The teacher has to identify a Development Support Group (DSG) and also develop a Personal Growth Plan (PGP)

- The SDT has to co-ordinate staff development, maintain and keep records of IQMS activities and ensure that application of quality standard is consistent

- The DSG provides mentoring and support for the teacher, provides feedback to the teacher and assists the teacher to develop his/her PGP

Most teachers seemed not to be conversant with the contents of IQMS documents and they could not spell their responsibilities clearly. The IQMS files for individual teachers were put in the principals' offices and some of them just looked like window dressing in order to submit fabricated evidence to the district offices. These gaps were evident upon empirical investigation whereby staff in these schools stated that there was neither seriousness nor monitoring of the IQMS documents. IQMS documents were attended to as and when the district office needs them for salary increment purposes only and did not assess the extent at which quality teaching and learning take place. The process of neglecting IQMS documents brought about doubts in the authenticity of IQMS system itself.

Some teachers indicated that they did not read the policy documents and did not understand what IQMS really is. As one teacher pointed out:

This is just one of those exercises from government which we are supposed to do. It is just a trauma with senior management and peers evaluating your lessons. I do not understand the contents of these IQMS documents

\subsection{Self-evaluation}

Most teachers indicated that self-evaluation and appraisal are not done regularly, that is once a year, as indicated in the policy documents. Only in one school, teachers said that it is done every year. Few teachers who had positive attitudes to the self-evaluation process tended to stress the opportunity provided by a formal scheme for facilitating teachers' selfappraisal. Comments from such teachers included the fact that teachers rarely have a chance to take stock of what they are doing. The IQMS has afforded teachers an opportunity to carry out some measure of self-evaluation which they construed as useful to their professional development. One teacher had this to say:

With self-evaluation we can do soul search and sort of rectify our mistakes and this helps us to develop as teachers. I think it is very important.

The above citation from one of the teachers succinctly encapsulates the power of the discourse of professional development emanating from the process of self-evaluation. Self-evaluation causes the teacher to reflect on his/her practice and methodology. The belief is that this type of instrument promotes a sense of responsibility and encourages higher standards and is, therefore, an excellent method for professional development (Biputh, 2008).

\subsection{Peer-appraisal}

For teachers working in what is considered a solitary culture, collaboration with peers is another feature of improving classroom activities. Deliberation among peers is a fundamental feature of professional development in any field. The results of this study revealed that most teachers have the perception that peer appraisal is not seen as furthering their team work. These teachers thus probably see peer appraisal as judgemental rather than a developmental activity and they were concerned that teachers may not be 'good enough' to handle this responsibility that goes hand in hand with making summative judgements about the quality of their colleagues' teaching performance. One teacher commented as follows:

Teachers are doing it just for the sake of doing it; we just do not go out there with the idea of developing our peers. It is just because you and I are friends, so you come to listen to my lesson... I also come to listen to yours...for few minutes...just to say.... I was there...that is all 
It is evident that this teacher is constructing peer appraisal in a discourse of compliance rather that of teacher development. On the other hand, whilst the IQMS calls for peer appraisal, there is a great variance between schools in South Africa. Some participants stated that some schools experience a shortage of teachers in certain subjects such as Mathematics. In such cases a Mathematics teacher may be appraised by a peer from another subject area. One teacher described the situation in this way:

Due to the scarcity of expertise in my subject area, I sometimes get someone from another subject area; who does not know the subject well to evaluate me. Clearly, this is just but a formality. This teacher will never give you clear advice and support

With regard to the involvement of DSG in observations of lessons of teachers, it became clear that it was something that is not generally happening as recommended in the IQMS documents. Furthermore, classroom appraisal and evaluation are not followed, as indicated in policy documents, at many of these schools. One teacher remarked that:

For the past two years only my peer assessed my lessons and no other teachers came to my classes. This is frustrating and this IQMS is not working

A large number of teachers perceive IQMS procedures as not beneficial to professional growth and they did not think that there is a tight fit between school staff development and the needs of teachers. Both these items beg for a closer collaboration between the designers and implementers of these programmes and the recipients of these programmes. The findings of this study further revealed that there are tensions revolving around the appropriate support available to teachers to improve their practices and it is for this reason that they cannot see evaluation as beneficial. The findings also found a generally negative attitude among teachers towards the implementation of IQMS. Most teachers and their Development Support Groups (DSGs) indicated that they do not know how to conduct an effective analysis of teacher performance and prioritise their development need, and have not been given sustained high quality training and opportunities to meet these expectations. In this case, many teachers blamed the district and the poor quality of some district officials.

\subsection{Feedback from stakeholders}

IQMS emphasises the flow of information from the DSG to the individual teacher and from the school to the district office and vice versa for the sake of "transparency and open discussion and quality controls" (ELRC, 2006:6). After an evaluation has taken place, the DSG must hold a discussion with a teacher in order to identify areas of strength and those that need improvements. This feedback will help the teacher to compile his or her personal growth plan. In most of the six schools, this feedback was not forthcoming. Most teachers from these schools alluded to the fact that in most instances, only peers evaluated them and the DSG never functioned. For that matter, teachers never received concrete feedback from their fellow teachers. The following remark was raised by one of the teachers:

In most cases I was evaluated by my fellow teacher alone and we agreed on a mark to be allocated. DSG never appraised me. This is the mark we sent to the principal to be recorded.

In order to improve schools and provide quality implementation of IQMS, district offices should give regular report to schools in terms of their performance and where teachers need to improve before the next evaluation process. Concerning this, teachers remarked that they never received any feedback from the district offices and in this manner IQMS became fruitless in terms of staff development and quality teaching.

\section{Conclusion}

The results of this study allow us to understand that in order for the IQMS to be effective, it should be well implemented, communicated and understandable to teachers. In this way teachers will be positively inclined towards the implementation of IQMS. Professional development and training are critical to school improvement. It means that, professional development, as an aspect of IQMS, could be a powerful strategy to improve the knowledge and skills of teachers in order to enhance the quality of teaching and learning. In order to improve schools and provide quality teaching to its learners, teachers need to develop themselves professionally and display a willingness to learn through initiatives such as IQMS. 


\section{References}

Biputh, B. (2008). An investigation of Educators' Perceptions of the Integrated Quality Management System in South African Schools. Unpublished DED thesis. Durban: Durban University of Technology.

Cohen, L., Manion, L. \& Morrisson, K. (2002). Research Methods in Education. $5^{\text {th }}$ Edition. New York: Routledge Falmer.

Craft, A. (2000). Continuing professional development: A practical guide for teachers and schools. London: Falmer press.

Day, C. (1999. Developing teachers: The challenges of lifelong learning. London: Falmer Press.

Department of Education (DoE) (1999). Developmental Appraisal for Educators. Pretoria: Government Printers.

Department of Education (2009). Ministerial Committee on a National Education Evaluation and Development Unit. Final Report, 16 June 2009. Government Gazette No. 32133. Pretoria: Government Printers.

Dhlamini, J.T. (2009). The role of Integrated Quality Management System to measure and improve teaching and learning in South African Further Education and Training Sector. Unpublished DED thesis. Pretoria: University of South Africa.

Education Labour Relations Council (2003). Integrated Quality Management System: Collective Agreement Number 8. Pretoria: ELRC.

Educators Workload Report (2005). Employment of Educators Act No. 76 of 1998. Pretoria: Government Printers.

Elmore, R. (2001). Professional Development and the practice of large-scale improvement in education. Harvard: Graduate School of Education.

Flick, U. (2007). Doing Focus Groups: The Sage Qualitative Research Kit. London: Sage.

Fullan, M. (1992). Successful School Improvement: The Implementation Perspective and Beyond. Milton Keynes: Open University Press.

Guskey, T.R. (2000). Evaluating professional development. Thosand Oaks: Corwin Press.

Joyce, B. (1993). School Culture through Staff Development. Yearbook of the Association for Supervision and Curriculum development. New York: ASCD Publishing.

Loxley, A., Johanston, K., Murcahn, D., Fitzgerald, H. \& Quinn, M. (2007). The role of whole-school contexts in shaping the experiences and outcomes associated with professional developing. Journal of In-service Education, 33, 265-287.

Matee, R.L. (2009). The Design of Continuous Professional Development in Technikons, with special reference to teaching function. Unpublished Masters Dissertation. Pretoria: University of South Africa.

Maxwell, J.A. (1996). Qualitative Research Design: An interpretive approach. Thousand Oaks, CA: Sage.

McLennan, A. (2000). Education Governance and Management in South Africa- cited in Smith, W.J. and Ngoma-Maema, W.Y. 2003, Education for all in South Africa: developing a national system for quality assurance. Comparative Education, 39 (3), 345-365.

McMillan, J.H. \& Schumacher, S. (2010). Research in Education-Evidence-Based Inquiry. $7^{\text {th }}$ Edition. New Jersey: Pearson

Meegan, S., Dunning, C., Belton, S. \& Woods, C. (2013). Teaching Practice: University supervisors' experience and perceptions of a cooperating Physical Education teacher education programme. European Physical Education Review, 35 (2), 199-253.

Menlo, A. \& Poppleton, P. (1990). A five-country study of the work perception of secondary school teachers in England, the United States, Japan, Singapore and West Germany (1986-1988). Comparative Education, 26, 173-182.

Merriam, S.B. (1998). Qualitative Research and Case Study Applications in Education. San Franscisco: Jossey-Bass.

Mestry, R. (1999). The training and development of principals in the management of educators. Unpublished DED thesis. Johannesburg: Rand Afrikaans University.

Mestry, R., Hendricks, L. \& Bisschoff, T. (2009). Perceptions of teachers on the benefits of teacher development programmes in one province of South Africa. South African Journal of Education, 29 (4), 475-490.

Minott, M.A. \& Willet, I.L. (2011). Student-teachers' supervision as a professional development activity: building work-related skills. Professional Development in Education, 37 (4), 537-550.

National Department of Education (NDOE) (2000). National Policy on Whole School Evaluation: Government Gazette, Notice No. 3102 of 2000, 423 (21539). Pretoria: Government Printers.

Phillips.R.J. (1996). An investigation into the necessity for transparency in managerial communication especially during teacher appraisal. Unpublished Med Dissertation. Johannesburg: Rand Afrikaans University.

Patton, M.Q. (2002). Qualitative Research and Evaluation Methods (3rd edition). Thousand Oaks, CA: Sage.

Sandberg, A., Anstett, S. \& Wahlgren, U. (2007). The value of in-service education for quality in pre-school. Journal of In-service Education, 33, 301-321.

Swartz, R. (1994). School Management, Teacher Development and Support. Johannesburg: University of the Witwatersrand.

Weber, E. (2005). New Controls and accountability for South African teachers and schools: The Integrated Quality Management System. Perspective in Education, 23 (2), 63-72. 